\title{
Transatlantica
}

Revue d'études américaines. American Studies Journal

\section{Sarah Le Menestrel. La voie des Cadiens. Tourisme et identité en Louisiane.}

Paris : Belin, 1999. 431 p.

\section{Nathalie Dessens}

\section{(2) OpenEdition}

\section{Journals}

Édition électronique

URL : http://journals.openedition.org/transatlantica/365

DOI : $10.4000 /$ transatlantica.365

ISSN : 1765-2766

Éditeur

AFEA

Référence électronique

Nathalie Dessens, « Sarah Le Menestrel. La voie des Cadiens. Tourisme et identité en Louisiane. », Transatlantica [En ligne], 1 | 2001, mis en ligne le 23 mars 2006, consulté le 29 avril 2021. URL : http:// journals.openedition.org/transatlantica/365 ; DOI : https://doi.org/10.4000/transatlantica.365

Ce document a été généré automatiquement le 29 avril 2021.

\section{cc) $(\mathrm{F})(\mathrm{E}$}

Transatlantica - Revue d'études américaines est mis à disposition selon les termes de la licence Creative Commons Attribution - Pas d'Utilisation Commerciale - Pas de Modification 4.0 International. 


\section{Sarah Le Menestrel. La voie des Cadiens. Tourisme et identité en Louisiane.}

Paris : Belin, 1999. 431 p.

Nathalie Dessens

1 Cet ouvrage, publié dans la collection « Histoire et Société, Cultures Américaines », est une belle étude ethnologique du récent renouveau de la culture cadienne en Louisiane. L'introduction explique clairement les cadres méthodologiques de cette étude de terrain, menée au sein même de la communauté cadienne. Elle évoque aussi les divers problèmes inhérents à l'enquête anthropologique, entre autres celui du rôle et des implications du chercheur. Le corps de l'ouvrage se compose de trois parties bien équilibrées, dont l'articulation suit un axe problématique clair et progressif.

2 La première partie porte sur l'image stéréotypée négative du cadien dans l'histoire de la Louisiane, et s'intéresse aux mouvements de revendication identitaire récents, accordant une place à part au groupe distinct des créoles noirs de Louisiane et insistant sur le rôle de la langue dans ce renouveau identitaire. Il est difficile en quelques lignes de donner une image exacte de la richesse de la réflexion qui prend en compte tous les aspects de cette société composite, et s'attache même à examiner la diaspora cadienne aux Etats-Unis, afin de mieux comprendre la dualité de l'identité de ces Américains qui demeurent attachés à leur spécificité culturelle.

3 La deuxième partie s'attache à l'étude de l'essor du tourisme francophone en Louisiane. Grâce à des analyses minutieuses de données économiques (complétées par des tableaux clairs et précis), l'auteur examine les ressorts de l'industrie touristique en Louisiane, le retour à une certaine légitimité de la culture cadienne au travers par exemple de la gastronomie et de la musique, ainsi que le développement d'un tourisme rural. L'auteur conclut sur le rôle du regard de «l'autre », touriste ou chercheur, dans le développement d'une identité culturelle qui puise dans l'intérêt montré par l'étranger une confirmation de la légitimité de ses revendications. 
4 La troisième partie est consacrée à la mise en scène de la culture cadienne par l'industrie touristique louisianaise. L'auteur étudie l'évolution des stéréotypes grâce à des études comparatives passionnantes de l'image de la Louisiane dans les guides touristiques. Elle insiste également sur l'intériorisation de cette nouvelle image valorisante et sur la façon dont la communauté utilise ces stéréotypes évolutifs pour s'auto-définir. Elle termine son analyse par un examen des interactions entre touristes et communauté cadienne.

5 L'ouvrage est une étude précise et pertinente du renouveau identitaire cadien en Louisiane. Il présente l'intérêt de se fonder sur des sources très riches et très diverses. L'auteur complète sa connaissance pointue de l'anthropologie du tourisme et de l'histoire louisianaise par des entretiens nombreux avec des agents locaux de ce renouveau identitaire, l'examen de guides touristiques et des observations de terrain. Le double avantage de cette étude est de présenter la vision extérieure d'un étranger en Louisiane mise en perspective par une ethnologue suffisamment introduite dans les milieux cadiens pour avoir connaissance de la face bien cachée de cette communauté. Cette position lui permet de mettre en évidence la distorsion entre l'image donnée par les Cadiens et la situation réelle de la communauté, avant de conclure sur le double impact de la politique touristique, qui met en lumière les clivages et les antagonismes de la société étudiée, mais révèle aussi les réelles possibilités de renforcer les liens communautaires.

6 Le livre offre également une bibliographie extrêmement fournie (sur l'histoire de la Louisiane, les stéréotypes cadiens, l'industrie touristique de l'État, les questions d'identité, d'ethnicité, de créolisation, ainsi que sur le tourisme dans une large perspective anthropologique), des cartes précises et claires, un index approprié, un glossaire de termes cadiens et créoles, ainsi qu'une fort utile chronologie sélective.

INDEX

Thèmes : Recensions

\section{AUTEUR}

NATHALIE DESSENS

Université de Toulouse-le Mirail 